DOI 10.48076/2413-9890.2021-102-13

УДК 662.99:66.047.57

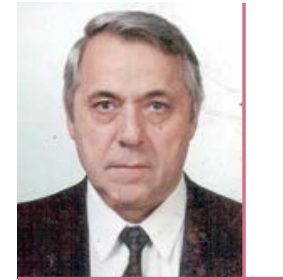

Торчинский А. И.

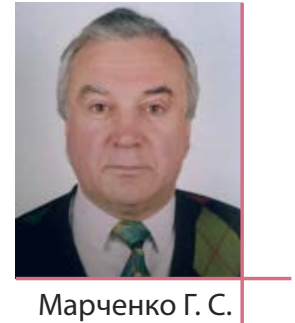

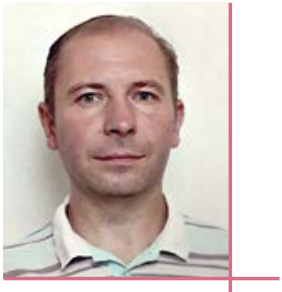

Андреев С. К.

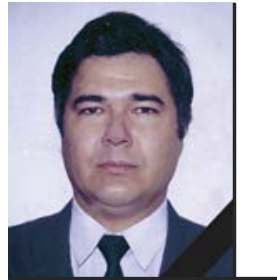

Макаренко В. А.

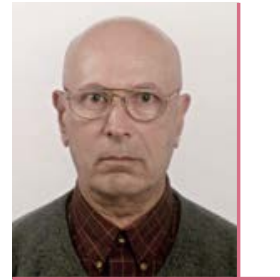

Волобуев С. В

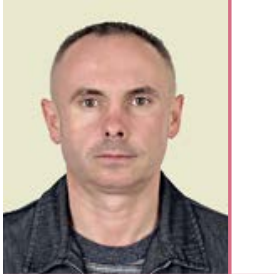

Химович С. В
Торчинский А. И., канд. техн. наук, ведущий научный сотрудник; Марченко Г. С., старший научный сотрудник;

Андреев С. К., младший научный сотрудник;

Макаренко В. А., старший научный сотрудник, канд. техн. наук,

Институт газа НАН Украины,

г. Киев, ул. Дегтяревская, 39,

凶tor_ingaz@ukr.net $\%+38$ (050) 3044999

Волобуев С. В., технический директор,

ООО «НПП ПРОМГАЗТЕХНО»,

г. Киев, ул. Парково-Сырецкая, За,

凶s.volobuiev@gmail.com $\$ 38$ (050) 3349975.

Химович С. В., ведущий инженер,

ООО «Львовская изоляторная компания»,

г. Львов, ул.Зеленая, 103,

凶 skhymovych@gmail.com $\approx+38$ (0322) 430026.
A. Torchinskyi, Cand. tech. Sci., Leading Researcher;

G. Marchenko, Senior Researcher;

S. Andreev, junior researcher;

V. Makarenko, Senior Researcher, Cand. tech. Sciences,

Institute of Gas of the National Academy of Sciences of Ukraine,

Kiev, st. Degtyarevskaya, 39,

凶tor_ingaz@ukr.net \%+38(050) 3044999.

S. Volobuev, technical director,

"PROMGAZTEHNO LLC",

Kiev, st. Parkovo-Syretskaya, 3a,

凶s.volobuiev@gmail.com $\mathrm{s}+38$ (050) 3349975.

S. Khimovich, Leading Engineer,

"Lviv Insulator Company LLC»,

Lviv, st. Zelenaya, 103 ,

凶 skhymovych@gmail.com $\approx+38$ (0322) 430026.

\title{
ЭНЕРГЕТИЧЕСКАЯ И ТЕПЛОТЕХНОЛОГИЧЕСКАЯ ЭФФЕКТИВНОСТЬ СУШКИ ПЕСКА И ДОЛОМИТА В СУШИЛЬНЫХ БАРАБАНАХ
}

\section{ЕНЕРГЕТИЧНА І ТЕПЛОТЕХНОЛОГІЧНА ЕФЕКТИВНІСТЬ СУШІННЯ ПІСКУ І ДОЛОМІТУ В СУШИЛЬНИХ БАРАБАНАХ ENERGY AND HEAT TECHNOLOGICAL EFFICIENCY OF DRYING SAND AND DOLOMITE IN DRYING DRUMS}

Аннотация. В Институте газа НАН Украины разработаны высокоэффективные теплогенераторы различной тепловой мощности, которые производят газовоздушный теплоноситель в широком диапазоне температур. Оснащение сушильных барабанов такими теплогенераторами обеспечивает более высокий технический и качественный уровень проведение сушильного процесса, что гарантирует получение конечной продукции высокого качества с одновременным значительным энергетическим эффектом.

Ключевые слова: газогорелочное устройство, горелочный модуль, теплогенератор, вращающийся барабан, процесс сушки, сжигание газа, энергетическая, технологическая, экологическая эффективность.

Анотація. В Інституті газу НАН України розроблено високоефективні теплогенератори різної теплової потужності, які виробляють газоповітряні теплоносії в широкому діапазоні температур. Оснащення сушильних барабанів такими теплогенераторами забезпечує більш високий технічний і якісний рівень проведення сушильного процесу, що гарантує отримання кінцевої продукції високої якості з одночасним значним енергетичним ефектом.

Ключові слова: газопальникові пристрої, теплогенератор, обертовий барабан, процесс сушки, спалювання газа, энергетична, технологічна, екологічна ефективність.

Abstract. Highly efficient heat generators of different heat capacity has developed at the Gas Institute of the National Academy of Sciences of Ukraine, which produce gas-air heat carriers in a wide range temperatures. Equipping drying drums with such heat generators provides a higher technical and high-quality level of the drying process, which guarantees the receipt of high quality final products with a significant energy effect.

Keywords: gas burner device, burner module, heat generator, rotating drum, drying process, gas burning, energy, technological, environmental efficiency.

Для многочисленного предприятий, которые используют сыпучие материалы в технологическом процессе производства различных материалов, качество сушки приобретает крайне важное значение, так как от конечных характеристик сыпучего материала зависит качество выпускаемого продукта.

Для сушки различных материалов используют сушильные барабаны в силу их конструктивной простоты, значительной производительности и энергетической эффективности - коэффициент полезного действия сушильных барабанов колеблется в интервале $80-82 \%$.
В традиционном исполнении в комплект сушильной установки входит следующие узлы: непосредственно сушильный барабан, к которому примыкают с одной стороны загрузочная камера с течкой для подачи сырьевого материала, с другой стороны - разгрузочная камера для удаления высушенного материала. К загрузочной камере примыкает так называемый подтопок, представляющий собой камеру сжигания, в которой установлены газогорелочные устройства. В подтопке при высокой температуре, создаваемой газогорелочными устройствами, происходит полное сжигание 
природного газа с воздухом. Таким образом, топка является стабилизатором горения: она гарантирует полное и безопасное сжигание газовоздушной смеси. Затем продукты полного сгорания из топки поступают в сушильный барабан, а необходимая температура для сушильного процесса обеспечивается подсосом холодного атмосферного воздуха за счет разрежения, создаваемого тягодутьевым устройством, установленном за разгрузочной камерой [1].

Исследование путей совершенствования технологических и энергетических параметров эксплуатации исходило из изучения и анализа статей теплового баланса указанного сушильного комплекса. Рассмотрим эти статьи. Самые большие теплопотери - это потери теплоты с продуктами, покидающими сушильный комплекс. Поэтому для снижения этих теплопотерь исследования были направлены прежде всего на интенсификацию теплоотдачи к сушильному материалу, что шло по пути увеличения внутренней теплообменной поверхности, что в свою очередь привело к тому, что температура уходящих газов снизилась до критической величины, за которой происходит конденсация водяных паров и они совместно с пылью, присутствующей в уходящих продуктах сгорания, в силу налипания на всех «хвостовых» поверхностях, не дают возможность дальнейшей нормальной эксплуатации узлов и оборудования, находящегося за сушильным барабаном. То есть, этот путь совершенствования был исчерпан.

Статья теплового баланса - потери теплоты в окружающую среду через металлические стенки сушильного барабана: - при появлении современных эффективных гибких теплоизоляционных материалов снижение этих потерь было достаточно легко решено теплоизоляцией наружной металлической поверхности этими материалами (войлоком из стекловолокна, базальтовым картоном, мулитокремнеземистым фетром и т. д.).

Следующая статья - потери теплоты через развитую поверхность подтопка: - они составляют значительную величину, достигающую $15 \%$ [1, 2]. Здесь же надо еще учесть тот фактор, что эксплуатация сушильных барабанов не является беспрерывным процессом, они работают в периодическом режиме. Поэтому остановки сушильного барабана приводят к значительным затратам времени и тепловой энергии на повторный разогрев футеровки топки. Кроме того, из-за частых температурных перепадов огнеупорные материалы футеровки топки подвергаются разрушению, что приводит к дополнительным затратам средств на восстановление работоспособности оборудования [3].

При появлении газогорелочных устройств, гарантирующих устойчивость горения газовоздушной смеси при низких температурах эксплуатации естественным техническим решением было исключение подтопка из цепочки сушильного комплекса, что значительно повышало его энергетическую эффективность.

Так в [3] приводится пример, где, вместо подтопка, на входном торце сушильного барабана установлена неподвижная вертикальная стенка с герметизаций ее с подвижной частью самого барабана. В вертикальной стенке установлены газогорелочные устройства, течка, подвижные шибера для регулируемого подсоса атмосферного воздуха.

В Институте газа Национальной академии наук Украины постоянно ведутся работы по разработке и исследованию различных газогорелочных устройств для термических и нагревательных печей, а также сушильных установок различных областей - от металлургии до промышленности строительных материалов. Так, для эксплуатации в условиях низких температур без внешних источников зажигания, таких как огнеупорные поверхности топки, в Институте газа были созданы инжекционные горелки с кольцевым стабилизатором (ИГКС) для природного и доменного газа. Эти горелки позволили осуществить стабильное (без отрыва факела) горение газовоздушного топлива и, таким образом, гарантировать безопасность эксплуатации в условиях бестопочного сжигания. В период 1987-1991 г.г. этими горелками были оснащены сушильные барабаны диаметром 3,5 x 28 м 1 шт., диаметром 2,8 × 20 м - 4 шт., диаметром 2 × 16 м 4 шт. Криворожского цементного комбината $[4,5]$. Эксплуатация инжекционных горелок с кольцевым стабилизатором показала, кроме гарантированной устойчивости горения, также полное сжигании природного газа, связанное, очевидно, с микросжиганием (или каталитическим сжиганием) за счет пересыпающихся частиц сыпучего материала: - в составе продуктов сгорания не было обнаружено компонентов недожога топлива.

Здесь следует отметить, что при установке в сушильных барабанах газогорелочных устройств по типу, как описано в [3, 4, 5], распределение температуры по поперечному сечению крайне неравномерно. Это влечет за собой снижение качества сушки, выражающегося в неравномерности влажности и даже химических свойств твердых частиц материала, выходящих из сушильного барабана. Последнее для многих технологий, например для производства стекла, имеет крайне негативные последствия на качество выпускаемой конечной продукции. Поэтому для таких производств технологический регламент сушки разрабатывается так, что качество получаемой продукции превалирует над желанием достичь энергетической выгоды.

Приведем пример - строительный песок: превышение влажности строительного песка приведет к нарушению конструктивных свойств объектов строительства и снизит их долговечность. Влажный песок теряет сыпучесть, становится рыхлым, а значит, непригодным для приготовления растворов. Также из него нельзя приготовить бетон высокого качества: всякий раз, когда влажность повышается на 1 \%, готовая бетонная смесь будет терять в прочности.

Еще один пример - формовочный песок: количество влаги влияет на газопроницаемость формовочного материала, а нарушение этого параметра вызывает брак при отливке. Также повышенная влажность песка снижает прочность формовочной смеси.

Песок для стекольной промышленности: сушка песка производится для доведения его характеристик до необходимых величин. Влажный песок трудно поддается перемешиванию с другими компонентами шихты, он плохо пересыпается, комкуется и т.д. Пересушенный песок также отрицательно сказывается на качестве стекла, как правило, это видно по изменению цвета со светло-бежевого на серый или темно-серый.

Сушка доломита: доломит сушат при $400-450^{\circ} \mathrm{C}$, так как при более высокой температуре начинается химическое разложение материала и он становиться непригодным для производства стекла.

Сушка глины. Если глиняная гранула попадает в область высоких температур, то на ее поверхности образуется корочка, которая останавливает процесс передачи влаги из середины наружу гранулы и, в таком случае, гранула глины выходить из сушильного агрегата с повышенной влажностью внутри, и пересушенная снаружи. В керамическом производстве при пересушке глины она теряет свои ценные пластические свойства. 
Приведенные примеры показывают, что для получения конечного продукта высокого качества, в процессе сушки температура теплоносителя должна поддерживаться достаточно точно - должна быть равномерно распределена - по всему поперечному сечению сушильного агрегата.

ООО «Львовская изоляторная компания» для производства стеклянных электрических изоляторов использует кварцевый песок и доломит. Для сушки кварцевого песка и доломита основным критерием качества сушильного процесса является равномерность и постоянство поля температур сушильного теплоносителя, поступающего в сушильный барабан. В связи с этим было принято решение использовать для отопления сушильных барабанов ООО «Львовская изоляторная компания» высокоэффективные смесительные газовоздушные теплогенераторы. Эти теплогененраторы оснащены струйными линейными горелочными модулями СГЛ-50 и СГЛ-15, которые разработаны Институтом газа НАН Украины совместно с НТУУ «Киевский политехнический институт» [7].

Струйные горелки типа СГЛ обладают уникальными энергоэкологическими характеристиками и эксплуатационными свойствами, так как они работают с постоянной высокой эффективностью в очень широком диапазоне тепловых мощностей и коэффициентов избытков воздуха.

Особенностью конструкции горелок является модульный принцип, что позволяет осуществлять их монтаж в установках по различным компоновочным схемам. Горелочный модуль содержит прямолинейный топливный коллектор со стабилизаторами в виде продольных, наклонных относительно одна другой пластин и сопловыми отверстиями, через которые осуществляется раздельный ввод в зону смешения, стабилизации и горения соответственно топливного газа и окислителя.

Реализуемая аэродинамическая схема подвода газа и окислителя обеспечивает наложение на диффузионный факел поля высокой турбулентности, генерируемого системой струй воздуха, что одновременно с дроблением зоны горения, состоящей из большого количества факелов, создает условия для интенсификации смесеобразования, стабилизации и сгорания топлива. Таким образом, эти теплогенераторы обеспечивают подачу потока теплоносителя с заданными равномерными полями скоростей и температур по всему сечению потока.

Теплогенераторы могут быть рассчитаны практически на любую мощность и на получение теплоносителя с любой тем- пературой. Максимальная мощность разработанных образцов достигает 20 МВт. Температура газовоздушного теплоносителя определяется конструктивными особенностями теплогенератора и рассчитывается в пределах $40 \ldots 80{ }^{\circ} \mathrm{C}$. В обозначении типоразмера теплогенератора цифры показывают расход природного газа (м³/4): например, ТГ-200 или ТГ800 имеют расход 200 и $800 \mathrm{~m}^{3} / 4$ соответственно [8, 9].

Горелочные модули установлены с зазором по отношению к стенкам воздушного канала теплогенератора таким образом, что внутри самого модуля сжигается газовоздушная смесь с коэффициентом избытка воздуха $a=1,5 \ldots 2,0$. Остальной воздух проходит в зазоре между пластинами-стабилизаторами горелочных модулей и стенками воздушного канала теплогенератора, а в смесительном камере теплогенератора происходит смешение горячих продуктов сгорания и холодного воздуха.

Основными агрегатами в системе сушки песка и доломита на сушильных барабанах ООО «Львовская изоляторная компания» использованы теплогенераторы ТГ-100 и ТГ-50, оснащенные горелочными модулями СГЛ-50. В сушильном барабане Д = 1,6 x 8 м - для сушки песка - установлен теплогенератор ТГ-100, а в сушильном барабане Д = 1 × 3,3 м - для сушки доломита - установлен теплогенератор ТГ-50.

Принципиальная схема теплогенератора как для сушильного барабана песка, так и для сушильного барабана доломита представлена на рис.1.

Теплогенератор состоит из следующих основных узлов: горелка СГЛ-50 - 1 шт. и 2 шт. соответственно, для теплогенератора ТГ - 50 и ТГ - 100 (1), распределительный воздушный конус - воздушный канал (2), камера смешивания (3), вентилятор подачи воздуха (4), в комплекте с воздушным шибером (4.1), запальная горелка (5) в комплекте с воздушным шаровым краном (5.1), с газовый краном (5.2), с автомобильной свечой зажигания (5.3), оптическое устройство контроля пламени (6), тубус (7) для визуального осмотра пламени внутри камеры сгорания, блок клапанов и регулирования расхода газа (8). Теплогенератор комплектуется блоком автоматического управления «КОТБУС» (9), который обеспечивает полный объем системы автоматики безопасности и регулирования температуры теплоносителя с возможностью работы без постоянного присутствия обслуживающего персонала.

Таблиця 4.

Техническая характеристика теплогенераторов

\begin{tabular}{|c|c|c|c|}
\hline № n/n & НАИМЕНОВАНИЕ & TГ-50 & TГ-100 \\
\hline 1. & Тепловая мощность, МВт (Гкал/ч) & $0,47(0,4)$ & $0,94(0,8)$ \\
\hline 2. & 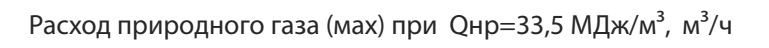 & 50 & 100 \\
\hline $3^{*}$. & Давление природного газа, кПа (мм в.ст.) & 3-10 (300-1000) & $3-10(300-1000)$ \\
\hline $4^{*}$. & Давление природного газа присоединительное, кПа (мм в.ст.) & $80(8000)$ & $80(8000)$ \\
\hline 5. & Температура теплоносителя за теплогенератором, ${ }^{\circ} \mathrm{C}$ & $300-400$ & $500-800$ \\
\hline 5. & Расход воздуха, нм3/ч & 2600 & 3000 \\
\hline 6. & Масса, кг & 120 & 200 \\
\hline 7. & Габаритные размеры, мм & $1375 \times 570 \times 775$ & $2195 \times 930 \times 775$ \\
\hline 8. & Аэродинамическое сопротивление мах, кПа (мм в. ст.) & $1,0(100)$ & $1,0(100)$ \\
\hline
\end{tabular}




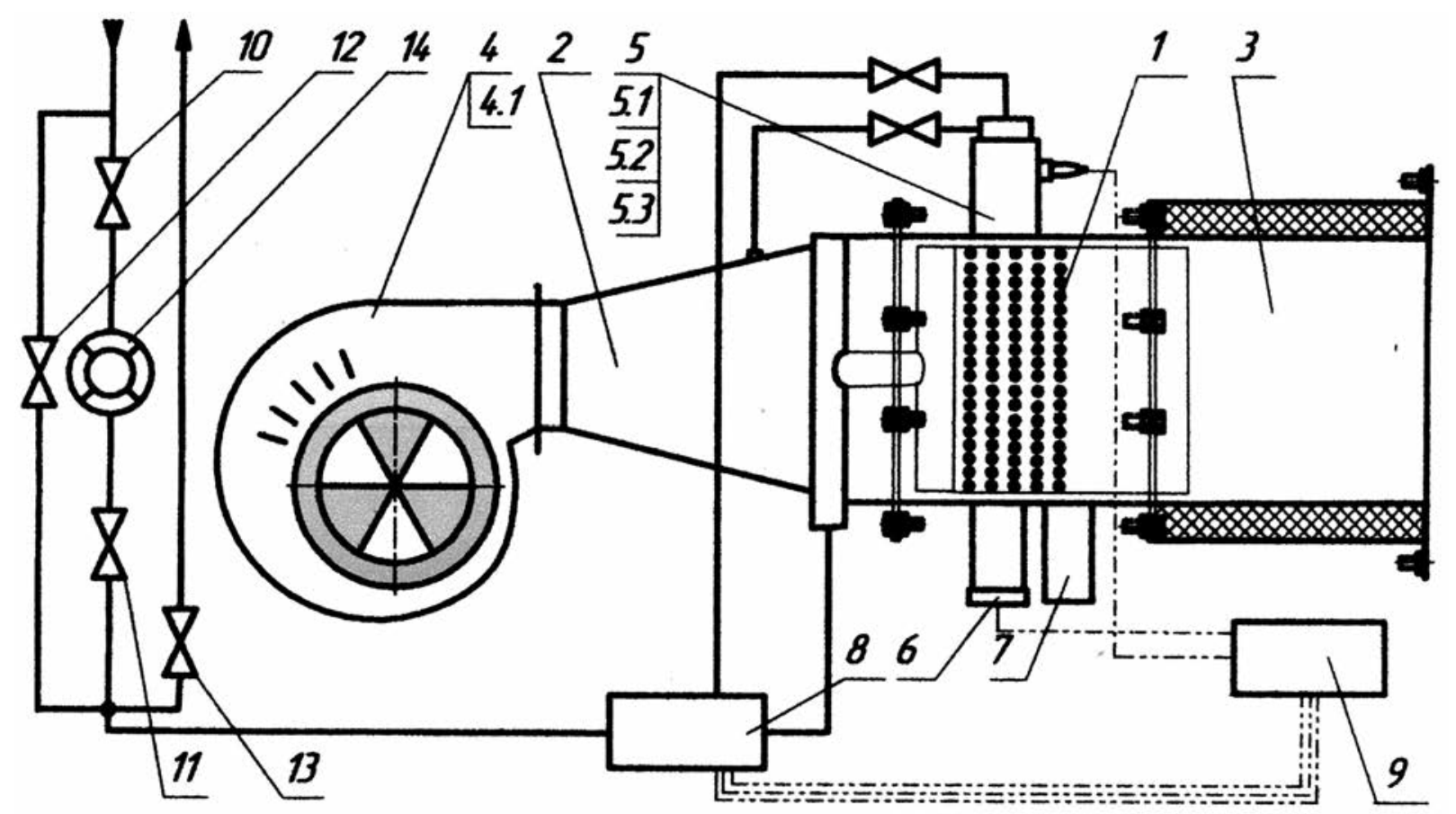

Рис.1. Принципиальная схема теплогенератора для сушильного барабана

1 - газовая горелка;

2 - конус - воздушный канал;

3 - камера смешивания;

4 - вентилятор подачи воздуха; 4.1 - воздушный шибер на вентиляторе;

5 - запальная горелка; 5.1 - воздушный кран; 5.2 - газовый кран; 5.3 - свеча розжига;

6 - оптическое устройство контроля пламени;

7 - тубус для визуального наблюдения;

8 - блок клапанов с регулятором расхода газа;

9 - блок автоматического управления «КОТБУС»;

10, 11, 12, 13, - шаровой кран;

14 - счетчик газа

\section{Выводы}

В Институте газа НАН Украины разработаны теплогенераторы типа ТГ на базе разработанных в Институте газогорелочных модулей СГЛ-50 со струйно-диффузионным принципом сжигания газа. Теплогенераторы предназначены для производства теплоносителя используемого в сушильных процессах. Эти теплогенераторы успешно внедрены на ООО «Львовская изолятор- ная компания» в сушильных барабанах для выполнения процесса сушки песка и доломита. Эксплуатация показала, что указанный комплекс «теплогенератор - сушильный барабан» имеет значительную энергетическую, технологическую и экологическую эффективность, что обусловливает улучшение качества выпускаемой продукции и технико-экономических показателей производства.

Література:

Роговой М.И. Теплотехническое оборудование керамических заводов. - М.1983.- 367 с.

2. Нохратян К.А. Сушка и обжиг в промышленности строительной кераміки. М.-1962.- 603 с.

3. Шейнман Е.Ш. Методические указания по пуску, испытанию и наладке печей и сушилок кипичных заводов. М. $1991-188$ c.

4. Торчинский А.И., Павловский Г.Н., Тихонов А.П. и др. Энергосберегающий способ отопления сушильных барабанов.// Строительные материалы и конструкции. - 1993. - № 4. - С.40 - 42

5. Торчинский А.И. Павловский Г.Н., Величко Ю.М. Экономия природного газа при сушке сырья в сушильных барабанах.// Международная научно-техническая конференция: Ресурсосберегающие технологии в производстве строительных материалов. - Макеевка: 1995. - С.132

6. ГОСТ 21204-97 - Межгосударственный стандарт. Горелки газовые промышленные. Технические требования. Минск.

7. А. с. СССР №877233. Газовая горелка/ Любчик Г.Н., Христич В.А., Марченко Г.С., Марковский А.В. и др.; заявл. 20.02.1980, опубл. 30.10.1981, Бюл. №40

8. Марченко Г.С., Макаренко В.А., Кундос В.Е., Любчик Г.Н. Высокоэффективные смесительные теплогенераторы широкого энергетического применения на основе струйных горелок. НТУ КПИ. // Енергетика: економика, технологии, екология. - 2004. - №4. - С 51-54.

9. Марченко Г.С., Любчик Г.Н., Макаренко В.А. Газовые теплогенераторы. // Экотехнологии и ресурсосбережение. 2009. - №4. - C 35-41. 